\title{
O SOFRIMENTO PSÍQUICO DE PROFESSORES UNIVERSITÁRIOS DAS LICENCIATURAS
}

\author{
Kelly Cristina Tesche Rozendo ${ }^{1}$, Carmen Lúcia Dias ${ }^{2}$ \\ ${ }^{1}$ Discente do Curso de Psicologia da UNOESTE. ${ }^{2}$ Docente do Mestrado em Educação da UNOESTE. Agência \\ Financiadora: Pibic/CNPq. E-mail: kellytesche@hotmail.com
}

\section{RESUMO}

Este artigo apresenta uma pesquisa sobre o sofrimento psíquico de professores universitários. Justificou-se tal temática por meio de estudos, que identificam o sofrimento nestes profissionais. A base teórica utilizada foi a Psicodinâmica do trabalho e a Psicologia Social. O objetivo foi analisar e entender o sofrimento psíquico dos professores universitários das licenciaturas, buscando destacar aspectos que compõem seu ambiente laboral. A metodologia contemplou a definição dos descritores, e a busca por artigos na base de dados da Biblioteca Virtual em Saúde da Bireme, entre os anos de 2006 a 2012. Os resultados apontam que as modificações nas leis de mercado refletem negativamente no trabalho acadêmico. A análise e discussão enfatizam o ambiente e as condições laborais, as relações sociais, a relação entre trabalho e psiquismo, e a saúde dos professores universitários. Conclui-se que o trabalho pode desencadear sofrimento psíquico e gerar problemas de saúde física e mental nos docentes.

Palavras-Chave: Sofrimento Psíquico; Professor; Universitário; Trabalho.

\section{INTRODUÇÃO E OBJETIVO}

Entende-se que a saúde atualmente é também o resultado de interações dinâmicas e complexas determinadas pelos domínios sociais, mentais, históricos e políticos, nos quais o trabalho possui caráter central. O processo de trabalho contemporâneo nas universidades possui elementos que influencia a saúde dos professores podendo gerar sofrimento no âmbito físico, psíquico e social (GRADELLA, 2010, MENDES et. al. 2007). Logo, reconhecendo que o trabalho pode propiciar algum tipo de sofrimento psíquico, apresenta-se como base teórica contribuições da Psicodinâmica do Trabalho e da Psicologia Social para a compreensão da temática.

No que se refere à Psicodinâmica do Trabalho, Dejours é o principal representante desta corrente teórica, a qual engloba visões singulares de cada ser humano de vivenciar o trabalho. Nesta perspectiva, o trabalho esta relacionado com desgaste mental podendo produzir adoecimento (GUIMARÃES; MARTINS, 2010). Já a Psicologia Social entende que cada indivíduo possui individualidade histórica e que o trabalho faz parte da história dos homens. Nesta visão, todo indivíduo é portador de inúmeras capacidades em suas relações com o trabalho e ao executar qualquer tarefa transmite afeto e subjetividade ao produto. Porém, quando inserido numa lógica de produção capitalista, o trabalho pode construir vias dolorosas, pois ocorre uma separação entre o indivíduo e o produto e uma cisão entre o trabalho e o afeto (CODO; SAMPAIO; 
HITOMI, 1993). Estas rupturas produzem sofrimento, o qual é disfarçado e mantido de forma invisível na organização do trabalho. Apenas o sofrimento físico é reconhecido, mas muitas vezes o sofrimento psíquico se traduz pelo surgimento de uma doença somática (DEJOURS, 1991).

À luz desses conceitos, é pertinente retomar a questão central deste trabalho, o sofrimento psíquico dos professores universitários. Neste sentido, a saúde mental destes profissionais é condição por ser de extrema responsabilidade para a educação, sendo sua função além de informativa e comunicativa um compromisso com a formação dos sujeitos humanos de maneira contínua (GRADELLA, 2010; MENDES et. al. 2007).

Apesar disto, a saúde mental destes profissionais é comprometida, pois as angústias e insatisfações estão presentes no âmbito do trabalho docente, podendo ser a instituição, a convivência, a burocracia, a alienação, a remuneração, a incapacidade de mudança, as intensificações do ritmo de trabalho, a competição acirrada, e a falta de autonomia causas de sofrimento e fatores capazes de promover depressões e sentimentos de indignidade, inutilidade e desqualificação. Estas consequências podem ir além do ambiente laboral e refletir negativamente na vida pessoal dos professores. Pois, o trabalho modifica a própria vida e a visão de mundo dos indivíduos, prejudicando a saúde mental dos profissionais (RIBEIRO; MARTINS, 2011; MENDES et. al. 2007; IWATA et. al. 2011; GRADELLA, 2010).

Assim sendo, considerando as implicações do ambiente de trabalho no mundo psíquico, físico e social dos profissionais da educação superior, o objetivo deste estudo foi analisar e entender o sofrimento psíquico de professores universitários das licenciaturas, buscando destacar características e elementos que compõem seu ambiente laboral. Logo, a relevância da temática justifica-se pela importância social de compreender e identificar falhas no sistema acadêmico a fim de possibilitar mudanças favoráveis, e por contribuir substancialmente com outras pesquisas desenvolvidas num grupo de pesquisa vinculado ao Mestrado em Educação do Programa de Pós Graduação da UNOESTE ${ }^{1}$, especificamente com a pesquisa de mestrado de uma orientanda deste grupo $^{2}$.

\section{METODOLOGIA}

Esta pesquisa de cunho bibliográfico (Pibic/CNPq) foi inscrita e aprovada na Coordenadoria Central de Pesquisa da Universidade do Oeste Paulista (CCPq/UNOESTE), sob protocolo número

\footnotetext{
${ }^{1}$ Grupo de Pesquisa "Contexto escolar e processo de ensino aprendizagem: ações e interações".

2 Pesquisa "A relação entre indisciplina e o desgaste do trabalho docente do ensino superior nas licenciaturas". 
1226 em 2012. A revisão constou de duas fases, sendo a primeira a definição dos descritores, a saber: estresse psicológico; trabalho; docentes. E a segunda, da busca por artigos científicos a partir da base de dados da Biblioteca Virtual em Saúde da Bireme, entre os anos de 2006 a 2012. Os resultados apontaram artigos que contextualizam o sofrimento psíquico de professores do ensino superior no âmbito da organização do trabalho, considerando reflexos das novas leis de mercado. Posteriormente, a análise e discussão buscaram identificar elementos da organização do trabalho que são capazes de promover sofrimento psíquico nos professores universitários das licenciaturas (MINAYO, 2004).

\section{RESULTADOS}

A pesquisa identificou nos artigos os efeitos da organização do trabalho sob o psiquismo, considerando possíveis repercussões da lógica da produção capitalista no mundo do trabalho dos professores universitários. Assim, de acordo com os resultados apontados por esta pesquisa evidencia-seque as modificações nas leis de mercado refletem negativamente no mundo do trabalho acadêmico, sendo contraproducente em todos os âmbitos da vida dos profissionais da educação superior.

Os dados obtidos revelam sofrimento psíquico vinculado a características do ambiente e condições de trabalho nas instituições acadêmicas de ensino superior, apresentando influencias das relações sociais no contexto laboral e no desempenho da função de docência, e indicando que a relação entre o trabalho e o psiquismo vincula-se profundamente com a saúde física e mental dos professores universitários.

\section{DISCUSSÃO}

Considerando aspectos importantes que refletem profundamente na temática do sofrimento psíquico de professores universitários, Lima e Lima-Filho (2009) apontam que o movimento de globalização e ajuste neoliberal, propiciou mudanças na política educacional e no trabalho em educação superior. Estas modificações refletem negativamente nas condições de trabalho, no próprio professor e no valor da educação, pois o novo modelo de configuração remete as instituições a um deterioramento e uma precarização das condições laborais, além de propiciarem mudanças na atuação, no desempenho e na função social dos docentes do ensino superior. 
Diante destas transformações no mundo do trabalho acadêmico, são apontadas situações de desvalorização da imagem docente que se caracteriza, entre outros fatores, por salários baixos, carência de recursos materiais e humanos, e aumento da intensidade e das responsabilidades laborais destes profissionais, cujas funções laborativas normalmente envolvem ritmo intenso, estressante e variável, onde os horários são desrespeitados. Esta jornada inclui longos períodos em pé, carregar peso de materiais didáticos, deslocamentos constantes, utilização do quadro de giz, inadequação do mobiliário, inquietude dos alunos, falta de motivação, trabalho repetitivo e monótono, além de violência verbal e muitas vezes física no ambiente acadêmico. Acrescenta-se ainda entre estes aspectos, o fato da sobrecarga laboral estar associada à falta de autonomia, conflitos, competição acirrada e ambiguidade de papel. Estes fatores podem gerar sobrecargas físicas e mentais trazendo sofrimento psíquico e consequências negativas para a saúde dos professores universitários (LIMA; LIMA-FILHO, 2009; SERVILHA; ARBACH, 2011; GARCIA; OLIVEIRA; BARROS, 2008).

Este sofrimento agrava-se com as inovações tecnológicas na contemporaneidade, pois se tornam obrigatórias novas formas de saber. Assim, o indivíduo é afetado e se conforma a um novo padrão de ser humano, o qual deve ser forte, intelectual, interativo, criativo, com iniciativa, versátil, flexível e com domínio e competência emocional ao executar sua função. Este novo ser humano em seu ambiente de trabalho submete-se a um modelo de organização, voltado supostamente a princípios humanitários, onde as situações vivenciadas descaracterizam o processo educativo. O novo indivíduo parece necessitar desconsiderar-se como sujeito de corpo, sentimento, emoção e desejo, e além de cuidar da formação dos alunos, deve ter responsabilidades com a própria formação enquanto profissional da educação superior (LIMA; LIMA-FILHO, 2009; GARCIA; OLIVEIRA; BARROS, 2008).

Diante de tantos compromissos e pressões, as relações sociais tornam-se determinantes para um ambiente saudável ou para o surgimento de sofrimento psíquico no contexto acadêmico. Desta forma, cabe salientar que o vínculo é o elemento básico da vida social podendo ser atingido pelo trabalho e modificar as relações interpessoais, a subjetividade e as atividades de maneira geral, influenciando na vida social, física e psíquica dos indivíduos. Portanto, as relações sociais e os vínculos humanos do mundo acadêmico refletem no conteúdo emocional e afetivo da atividade exercida (GRADELLA, 2010, MENDES et. al. 2007; GUIMARÃES; MARTINS, 2010).

Estes vínculos sociais quando desenvolvidos de maneira adequada, segundo Garcia, Oliveira e Barros (2008) promovem ambiente favorável capazes de ajudar no enfrentamento de 
dificuldades e adversidades dando suporte a níveis elevados de angústia e falta de sentido. No entanto, quando estes vínculos emocionais não são realizados de maneira adequada impossibilitam os laços que humanizam, podendo surgir o sofrimento psíquico, pois o trabalhador perde o significado de sua tarefa e função, e não consegue compreender o motivo da existência do trabalho e do porque o executa (GRADELLA, 2010, MENDES et. al. 2007; GUIMARÃES; MARTINS, 2010).

Este sofrimento pode ser incrementado pelo fato de que o trabalho reflete na vida privada dos profissionais da educação superior, e consequentemente na vida social destes trabalhadores. Pois, a exigência de dedicação exagerada as atividades docentes dificulta a integração na vida além do espaço laboral, e desta forma intensifica-se um processo negativo de trabalho que se vincula a um aumento do sofrimento podendo gerar problemas de saúde. Assim, identifica-se que há relação entre as condições de trabalho e o psiquismo, sendo o ambiente laboral um fator de risco que pode causar dano físico ou mental aos profissionais (GARCIA; OLIVEIRA; BARROS, 2008; SERVILHA; ARBACH, 2011; GUIMARÃES; MARTINS, 2010; LIMA; LIMA-FILHO, 2009).

Neste contexto, considerando a saúde psíquica dos profissionais das instituições acadêmicas, é importante compreender o trabalho a partir da forma como cada trabalhador o experimenta, o vivencia, e o constrói coletivamente. Não é possível falar do trabalho de maneira generalizada. Logo, o trabalho do professor universitário é processado por cada profissional de maneira distinta, e as atitudes de cada sujeito pode levar a promoção da qualidade de vida ou não. Neste sentido, Lima e Lima-Filho (2009) afirmam que o impacto do sofrimento produzido pelo trabalho no psiquismo depende de variáveis individuais. Diante disto, segundo Garcia, Oliveira e Barros (2008) o trabalho deve tratar-se de uma atividade viva que inventa e recria de acordo com as necessidades e com as singularidades de cada trabalhador, a fim de amenizar o sofrimento.

Conforme apontam Dejours, Dessors, Desriaux (1993), o psiquismo dos trabalhadores é refletido tanto por aspectos positivos, quanto negativos do trabalho. Considerando os pontos positivos, a referência a satisfação relaciona-se a flexibilidade, liderança e disponibilidade. De acordo com Lima e Lima-Filho (2009) o ambiente laboral pode ser um espaço de reafirmação da autoestima, desenvolvimento de habilidades, expressão das emoções, podendo ser fonte de construção de saúde. Porém, para que isso aconteça o trabalhador necessita ter uma visão globalizante do trabalho, pois sua fragmentação faz com que o trabalho perca seu significado, produzindo sofrimento ao trabalhador e comprometimento na saúde física e mental dos profissionais. 
Assim sendo, o processo de saúde e doença é também construído no trabalho, de natureza biológica, psicológica e social. Logo, considera-se que a organização do trabalho dos professores universitários funciona como fonte de exaustão e adoecimento, desestabilizando e colocando em risco a saúde física e mental dos trabalhadores. Lima e Lima-Filho (2009) indicam que ser professor na atualidade é uma das ocupações mais estressantes. Segundo Servilha e Arbach (2011) os professores de ensino superior demonstram elevado grau de sofrimento psíquico devido a aspectos negativos da organização do trabalho. Este sofrimento pode produzir doenças somáticas.

Neste sentido, os problemas de saúde física, mental e enfermidades relacionadas ao trabalho mais relevantes associam-se a sobrecarga ocupacional. A pesquisa de Lima e Lima-Filho (2009) chama a atenção pela diversidade de queixas relacionadas a sintomas psicossomáticos como o nervosismo, estresse, cansaço mental, esquecimento, insônia, frustração, ansiedade, angústias, fobias, crises de pânico e depressão. Estes sintomas podem resultar em manifestações como desinteresse, fadiga mental, apatia, irritabilidade, falta de motivação, entre outros aspectos. Ainda do autor, este desgaste mental, por conseguinte gera baixa imunidade, promovendo crises enfermas.

Corroborando a posição supracitada, Servilha e Arbach (2011) acrescentam além dos problemas relacionados à saúde mental, problemas musculoesqueléticos (dores nas costas, pernas e braços), enxaquecas, crises hipertensivas, problemas dermatológicos e quadros de gripe constantes entre os professores do ensino superior. Enfatiza-se ainda que entre as queixas e doenças mais frequentes encontram-se a tendinite, bursite, rinite, sinusite, doenças da laringe, das cordas vocais e respiratórias. Segundo Suda et. al. (2011), a maioria dos profissionais do ensino superior apresentam dor na região do pescoço e lombar, e destacam sentimentos de nervosismo, tensão, cansaço e problemas referentes ao fato de ter que lidar com o cotidiano.

Diante do exposto, cabe salientar que segundo Lima e Lima-Filho (2009) é escassa a literatura sobre as condições laborais e de saúde de professores universitários. Contudo, na última década o trabalho docente passou a ser tema em vários estudos, os quais revelam processos de adoecimento em seu âmbito laboral. No Brasil, a partir da década de noventa cresceu o número de investigações sobre este temática, o que confirma a relevância da problemática e instiga novas pesquisas necessárias para uma contribuição social eficaz e transformadora.

\section{CONCLUSÕES}


Partindo de preocupações com a educação superior e de inquietações particulares referentes ao desgaste mental dos professores universitários e sua relação com o ambiente de trabalho despertou-se demandas e desejos de aprofundar conhecimentos sobre esta temática, a fim de refletir sobre possíveis intervenções capazes de amenizar estes desgastes. Para isso, a presente pesquisa buscou analisar elementos do ambiente laboral dos docentes que podem ser fatores desencadeantes do sofrimento psíquico. Lima e Lima-Filho (2009) supõem que conhecimentos relacionados à dinâmica de produção do desgaste mental podem viabilizar prevenções necessárias para diminuição da carga psíquica. Para este fim, o referencial teórico utilizado neste estudo, contou com contribuições da Psicodinâmica do Trabalho, da Psicologia Social e de artigos referentes à temática em questão. A literatura analisada colaborou para o entendimento de pontos significativos referentes às inquietudes elaboradas no início e durante a pesquisa.

Visando desafiar mudanças no contexto da educação superior, esta pesquisa espera fornecer subsídios para arraigar conhecimentos de dimensões profundas e enriquecimento social. Dentro desta perspectiva, o papel dos professores universitários torna-se fundamental, pois estes devem ser capazes de refletir sobre sua situação laboral e questionar sua prática e finalidade, para assim mobilizar a construção de novas leis laborais que possam amenizar o sofrimento. Sem embargo, para que estes profissionais possam contribuir com autonomia e determinação é preciso coerência na realização deste movimento no sentido da ética emancipatória com olhar cauteloso na tentativa de dar conta desta complexidade. É necessário explorar a maneira com que o trabalho impacta a vida dos trabalhadores e tentar modificar os embates negativos. No entanto, para isto não apenas o discurso deve ser flexível, mas o trabalho deve deixar de ser efetivamente duro.

Finalizando, espera-se que as expectativas pretendidas tenham sido atendidas e que o conhecimento apresentado forneça elementos que colaborem com a diminuição e o reconhecimento do sofrimento psíquico no campo do trabalho acadêmico, cooperando em possíveis intervenções. Não obstante, sugere-se que pesquisas futuras sobre esta temática sejam realizadas a fim de estender conhecimentos. Neste sentido, os resultados aportados por este estudo subsidiarão uma nova pesquisa, desta vez, empírica, referente ao sofrimento psíquico no âmbito do trabalho dos professores universitários de um curso de licenciatura em Pedagogia de uma Instituição de Ensino Superior (Pibic/CNPq). Assim sendo, este estudo terá continuidade em uma amplificação de ordem empírica com abordagem qualitativa do tipo estudo de caso, 
aprovado na Coordenadoria Central de Pesquisa da Universidade do Oeste Paulista (CCPq/UNOESTE), sob protocolo número 1601.

\section{REFERÊNCIAS}

CODO, W. SAMPAIO, J.J. C. HITOMI, A.H. Indivíduo, trabalho e sofrimento: uma abordagem interdisciplinar. Petrópolis/Rio de Janeiro: Vozes; 1993.

DEJOURS, C. A Loucura do trabalho, estudo de psicopatologia do trabalho. São Paulo: Cortez; Oboré. 4 ed.; 1991.

DEJOURS, C. DESSORS, D. DESRIAUX, F. Por um trabalho, fator de equilíbrio. Rev. de Adm. Empres. São Paulo, v. 33, n.3, p. 98-104, maio/jun. 1993.

GARCIA, A. L. OLIVEIRA, E. R. A. BARROS, E. B. Qualidade de vida de professores do ensino superior na área da saúde: discurso e prática cotidiana. CogitareEnferm. Jan/Mar; 13(1): 18-24. 2008.

GUIMARÃES, F. A. L. MARTINS, M. C. F. Valores e prazer-sofrimento no trabalho: um estudo com profissionais de nível superior. Estudos de Psicologia, Campinas, 27(2) , p.133-145,abr/ jun 2010.

GRADELLA, O. J. Sofrimento psíquico e trabalho intelectual do docente universitário. Cadernos de Psicologia Social do Trabalho. Marília/SP, v. 13, n. 1, p. 133-148, 2010.

IWATA, H. OLIVEIRA, D. D. IVERS, J. F. RIBEIRO, S.F.R. Estratégia de Saúde da Família Saúde do Agente Comunitário de Saúde a partir de um Diagnóstico Organizacional. Anais do 19 encontro de serviços-escola de psicologia do estado de São Paulo: o papel da formação em psicologia frente as demandas de saúde pública.São Paulo, ago/set. 2011.

LIMA, M. F. E. M. LIMA-FILHO, D. O. Condições de trabalho e saúde do/a professor/a universitário/a. Ciências \& Cognição; v. 14 (3): 062-082. 2009.

$<$ http://www.cienciasecognicao.org>.

MENDES, L. CHAVES, C.J.A. SANTOS, M. C. NETO, G.A. M. Da arte ao ofício: vivências de sofrimento e significado do trabalho de professor universitário. Rev. Mal-estar e subjetividade. Fortaleza, v. VII, n. 2, p. 527-556, set. 2007.

MINAYO, M.C.S. O desafio do conhecimento: pesquisa qualitativa em saúde. São Paulo: Editora Hucitec, 2004.

RIBEIRO, S. F. R. MARTINS, S. T. F. Sofrimento Psíquico do Trabalhador da saúde da Família na Organização do Trabalho. Psicologia em estudo. Maringá, v. 16, n. 2, p. 241-250, abril/jun. 2011.

SERVILHA, E. A. M. ARBACH, M. P. Queixas de saúde em professores universitários e sua relação com fatores de risco presentes na organização do trabalho. DistúrbComun,São Paulo, 23(2): 181191, agosto, 2011. 
SUDA, E. Y. COELHO, A. T. BERTACI, A. C. SANTOS, B. B. Relação entre nível geral de saúde, dor musculoesquelética e síndrome de burnout em professores universitários. Fisioterapia e Pesquisa,São Paulo, v.18, n.3, p. 270-4, jul/set. 2011. 